\title{
Pseudo-Tumoral Cutaneous Leishmaniasis
}

\author{
Frikha F, Bahloul E, Amouri M, Turki H
}

Department of Dermatology, Hedi Chaker Hospital, Sfax Tunisia frikhafat@gmail.com

Abstract: Cutaneous leishmaniasis may be misdiagnosed because of its similarity to other skin diseases.

Keywords: Cutaneous leishmaniasis, pseudotumoral, atypical, polymorphism

\section{INTRODUCTION}

In an endemic area, it is necessary for the physician to be aware that any atypical lesion, especially chronic form, should be investigated for cutaneous leishmaniasis. We herein report a rare case of pseudo-tumoral cutaneous leishmaniasis.

\section{CASE REPORT}

A 53-year-old man from a rural area in Tunisia presented with a 2 month history of asymptomatic and persistent vegetating lesion on the dorsal aspect of the right ankle (Figure 1). Physical examination showed a $15 \mathrm{x} 6$ $\mathrm{cm}$ vegetating and pseudo-tumoral lesion with a papillomatous aspect and large ulceration on surface, a soft moist consistency and an indurated base (Figure 2). The rest of the examination was unremarkable. Optical examination of the smears (taken from two sites), after May-Grünwald-Giemsa staining, revealed amastigote forms of the leishmania parasite. Polymerase-chain-reaction (PCR) assay identified Leishmania Major (L. major). The diagnosis of pseudo-tumoral cutaneous leishmaniasis (CL) was confirmed. The patient was treated with meglumine antimoniate intramuscular $(60 \mathrm{mg} / \mathrm{kg} /$ day $)$ during three weeks. There was a modest and partial response to treatment.

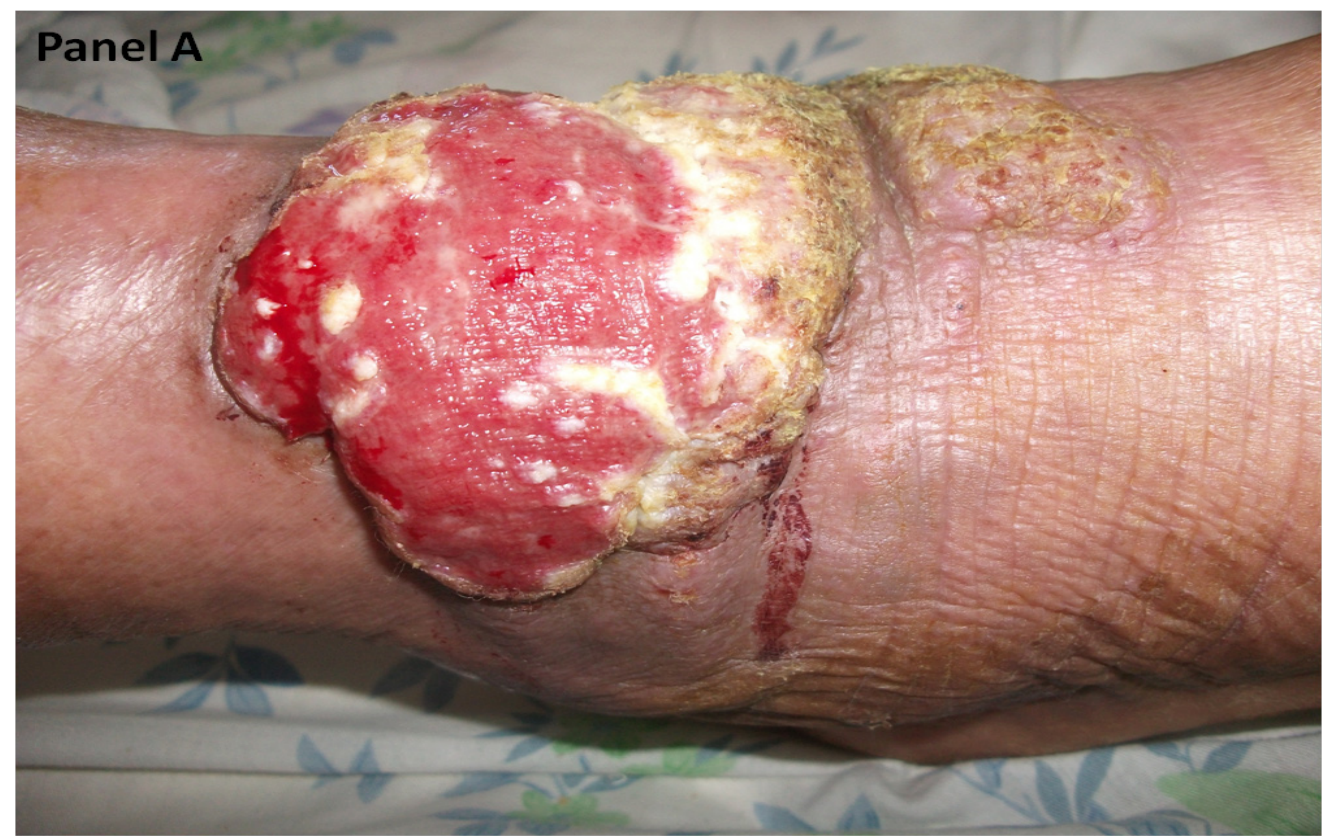

Figure1. Vegetating lesion on the dorsal aspect of the right ankle. 


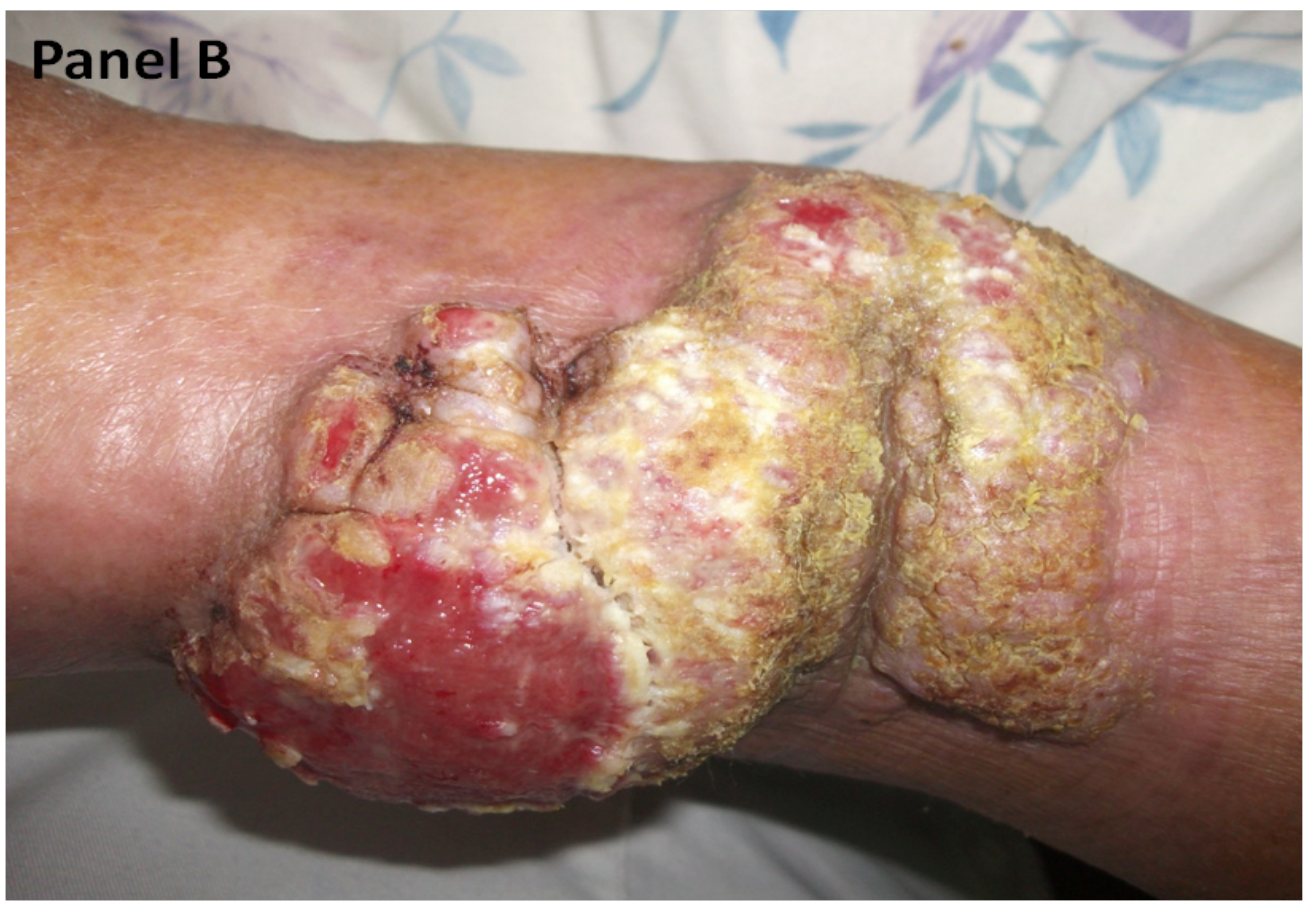

Figure2. a $15 \times 6 \mathrm{~cm}$ lesion with a papillomatous aspect and large ulceration on surface, a soft moist consistency and an indurated base.

\section{DiscusSiON}

Several atypical forms of CL have been described (1). These lesions can mimic many other diseases and confound the physicians, which may delay the precise diagnosis, submitting the patients to unnecessary treatments and contributing to the transmission chain of the parasite (1)"ISBN":"1873-6254 (Electronic.

Atypical lesions include the following forms: erythematous volcanic ulcer, diffuse, eczematous, lupoid, verrucous, dry, zosteriform, nodular lesions, erysipeloid, sporotrichoid, annular, paronychial, palmoplantar, psoriasiorm and pseudo-tumoral forms (1)"ISBN":"1873-6254 (Electronic (2). Pseudo-tumoral is an uncommon form of CL. Clinically, it is characterized by a macaroon-shaped lesion with an embossed proliferation simulating squamous cell carcinoma and amelanotic melanomas (3) (4). It is preferentially localized on the lower limbs (5).

The clinical polymorphism of CL caused by L. major seems to be rather high, which could reflect the complexity of the disease, involving several factors related to the parasite (virulence, parasitic load, and the presence of other pathogens), the type and duration of the clinical lesion, the geographic location, the disease reservoir, and the host's immune status (3) (2). Pentavalent antimonials, including meglumine antimoniate (Glucantime ${ }^{\circledR}$ ), remain the first line of treatment of atypical forms of CL (5).

\section{CONCLUSION}

CL caused by L. major exhibits a large clinical polymorphism and consequently should be included in the differential diagnosis of many common and uncommon dermatological diseases such as tumors.

\section{REFERENCES}

1. Meireles CB, Maia LC, Soares GC, Teodoro IPP, Gadelha M do SV, da Silva CGL, et al. Atypical presentations of cutaneous leishmaniasis: A systematic review. Acta Trop. 2017;172:240-54. 
Pseudo-Tumoral Cutaneous Leishmaniasis

2. Bari AU, Rahman S. Many faces of cutaneous leishmaniasis. Indian J Dermatol Venereol Leprol. 2008;74:23.

3. Remadi L, Najoua Haouas, Dhekra Chaara, Darine Slama, Najla Chargui, Radhia Dabghi HJ, Babba HMH. Clinical Presentation of Cutaneous Leishmaniasis caused by Leishmania. 2017;5000:1-8.

4. Masmoudi A, Ayadi N, Boudaya S, Meziou TJ, Mseddi M, Marrekchi S, et al. Polymorphisme clinique de la leishmaniose cutanée du centre et sud tunisien. Clinique. 2006;36-40.

5. Frikha F, Boudaya S, Bahloul E, Mesrati H, Amouri M, Turki H. Une lésion tumorale du visage. La Rev Médecine Internedecine interne. 2019;

Citation: Frikha F, Bahloul E, Amouri M, Turki H. "Pseudo-Tumoral Cutaneous Leishmaniasis". American Research Journal of Dermatology; 1(1): 1-3.

Copyright (C) Frikha F, Bahloul E, Amouri M, Turki H. This is an open access article distributed under the Creative Commons Attribution License, which permits unrestricted use, distribution, and reproduction in any medium, provided the original work is properly cited. 